\title{
Prevention of seasonal affective disorder in daily clinical practice: results of a survey in German-speaking countries
}

\author{
B. Nussbaumer-Streit ${ }^{1,2}$, D. Winkler ${ }^{1 *}$, M. Spies ${ }^{1}$, S. Kasper ${ }^{1}$ and E. Pjrek ${ }^{1}$
}

\begin{abstract}
Background: Seasonal affective disorder (SAD) is a seasonally recurrent type of major depression. This predictable aspect makes it promising for preventive treatment. However, evidence for the efficacy and harm of preventive treatment of SAD is scarce, as are recommendations from clinical practice guidelines. The aim of this study was to assess the current use of preventive treatment of SAD in clinical practice in German-speaking countries for the first time.

Methods: We conducted a postal and web-based survey sent to the heads of all psychiatric institutions listed in the inventory "Deutsches Krankenhaus Adressbuch, 2015" that contains all psychiatric hospitals in Germany, Austria, and Switzerland.

Results: One hundred institutions (out of 533 institutions, 19\%), which treated in total more than 3100 SAD patients in the years 2014/2015, responded. Of those, 81 reported recommending preventive treatment to patients with a history of SAD. There was no consensus on the optimal starting point for preventive treatment. Most of the institutions that implemented prevention of SAD, recommended lifestyle changes (85\%), antidepressants (84\%), psychotherapy (73\%), and light therapy (72\%) to their patients. The situation was similar in northern and southern regions.

Conclusions: Most hospitals recommended the use of preventive treatment to SAD patients, although evidence on efficacy and harm is limited. A wide variety of interventions were recommended, although guidelines only include recommendations for acute treatment. To assist psychiatrists and patients in future decision making, controlled studies on preventive treatment for SAD that compare different interventions with one another are needed.
\end{abstract}

Keywords: Seasonal affective disorder, Winter depression, Prevention, Austria, Germany, Switzerland

\section{Background}

Seasonal affective disorder (SAD), winter-type, is a subtype of major depression, characterized by a recurrent pattern in which depressive episodes start in fall/winter and remit in spring $[1,2]$. It affects $2-8 \%$ of the total population in Europe, depending on latitude [3-7]. In German-speaking countries approximately $2.5 \%$ of the population suffers from SAD $[8,9]$. About $80 \%$ of those diagnosed with this illness will face a recurrent depressive episode the following winter [10], which has detrimental effects on their quality of life. Five to 11 years following initial diagnosis,

\footnotetext{
* Correspondence: dietmar.winkler@meduniwien.ac.at

'Department of Psychiatry and Psychotherapy, Medical University of Vienna, Währinger Gürtel 18-20, 1090 Vienna, Austria

Full list of author information is available at the end of the article
}

SAD resolves in only $14-18 \%$ of patients, persists in $22-42 \%$, and develops into a non-seasonal major depression in $33-44 \%$ of patients $[11,12]$.

Since decreased seasonal exposure to environmental light is thought to be a trigger for developing SAD, light therapy is the first line of treatment [13]. At the neurochemical level, changes in both the serotonergic and catecholaminergic transmitter systems seem to play key roles in SAD [14]. Therefore, antidepressants have become the second choice of treatment. Of these, only one (bupropion extended release [XL]) is currently approved for the prevention of SAD [15]. Treatment options other than light therapy and antidepressants include agomelatine [16], melatonin [17], psychological interventions [18-21], as well as lifestyle and diet changes [22]. 
The seasonal recurrence of depressive episodes provides the rationale for these interventions as a preventive treatment of SAD [23]. Implementing them in symptom-free periods could avoid the development of new depressive episodes in the next fall/winter. However, very little is known about the efficacy and potential harms of preventive treatments in SAD patients. A recent systematic review demonstrated that the preventive use of the antidepressant bupropion XL reduced the number of male and female patients developing a new depressive episode in the next winter by $44 \%$ compared to placebo [24]. An additional systematic review on preventive light therapy in SAD patients identified only one study with high risk of bias, allowing no valid conclusions [25]. A systematic review on agomelatine, and melatonin was not able to identify any randomized controlled trials [26]. A recent randomized controlled trial on preventive psychotherapy showed that cognitive behavioural therapy led to lower recurrence of SAD-episodes in the following winters compared to light therapy (27.3\% compared to 45.6\%) [27].

The German clinical practice guideline on depression recommends the use of light therapy for SAD patients during the period of risk (fall/winter), but not during the summer months [28]. No other recommendations regarding prevention of SAD episodes are provided. Thus, clinicians are forced to rely on recommendations for patients with a non-seasonal major depression. For prevention of recurrent depressive episodes in these patients, continuation treatment with antidepressants and psychotherapy is recommended [28]. Despite much uncertainty, patients and clinicians may decide for preventive interventions in daily clinical practice. To date, however, there is no published evidence to what extent preventive interventions are used, or which interventions are used for this purpose, if any. The objective of our study was to determine clinical practice patterns regarding the prevention of SAD episodes in German speaking countries.

\section{Methods}

To achieve our objective, we employed an international survey in German-speaking countries. The study was approved by and registered with the ethical review board of the Medical University of Vienna (EC No 1586/2015).

\section{Sampling frame}

We used the inventory "Deutsches Krankenhaus Adressbuch, 2015" [29] that contains all psychiatric institutions in German speaking countries as our sampling frame. We removed 58 institutions, after validation via an internetsearch, because they had been closed, merged with other psychiatric institutions, or exclusively provided child and adolescent psychiatric care. Thus, the basic survey population comprised 533 psychiatric hospitals and departments in Austria, Germany, and Switzerland.

\section{Survey method}

We developed a questionnaire in the German language according to established standards [30] and partly based on a questionnaire used in a former study on the use of light therapy [31]. We pre-tested the questionnaire with four psychiatrists working at the Medical University of Vienna and checked face-validity within our research team. The questionnaire was structured into a general part on acute treatment of SAD and a specific part on preventive treatment of SAD. The first part included one question on the number of patients treated for SAD in the institution and one assessing what interventions were used to treat acute depressive episodes in SAD patients. We asked about the use of light therapy, antidepressants, agomelatine, melatonin, methylphenidate, psychotherapy, lifestyle changes, diet changes, and alternative approaches. We named examples of lifestyle changes (e.g. sports, brighter homes), diet changes (e.g. vitamin $\mathrm{D}$, no caffeine intake), and alternative approaches (e.g. meditation, yoga, acupuncture) to give an idea of what type of interventions were included in this category.

In the second part we asked if hospitals recommend interventions to prevent the onset of a new depressive episode in the next fall/winter in patients with a history of SAD and what timing they prefer for preventive treatment. We explicitly asked if light therapy, antidepressants, agomelatine, melatonin, methylphenidate, psychotherapy, lifestyle changes, diet changes, and alternative approaches were used as preventive treatment, and if so in how many patients, and for how long. We also asked participants to name the specific type of intervention used; e.g. the name of the antidepressants used for preventive treatment of SAD. Head of participating departments and hospitals were asked to use the years 2014/2015 as reference periods and to reflect the policies in their hospitals rather than their individual opinion in their answers.

We conducted the survey between December 2015 and April 2016. First, we sent a postal questionnaire accompanied by a cover letter and a stamped responseenvelope to the heads of all psychiatric departments and hospitals from our survey population. In order to reach out to non-responders we set up a web-based survey based on the questionnaire with the software SurveyMonkey [32] in February 2016. We sent a survey-invitation to all non-responders as well as two reminder e-mails, one in March 2016, and one in April 2016, and called them once per phone.

\section{Analysis}

We analysed responses mainly using descriptive statistics. Main outcomes of interest were 1) the proportion of departments and hospitals recommending preventive treatment to SAD patients, 2) the timing of preventive 
treatment, 3) the frequency of different interventions recommended for preventive treatment. In addition, we wanted to know the proportion of patients receiving, as well as the timing and specification of, each preventive treatment (e.g. type of antidepressant).

Switzerland, Austria, and Germany have only a small latitude cline $\left(47^{\circ}-54^{\circ}\right)$, but differences in sunshine hours during winter, e.g. in February more than 100 sunshine hours in Austria and in the south of Germany compared to less than $50 \mathrm{~h}$ in the north of Germany [33, 34]. We assumed that this might correlate with greater demand for preventive treatment in northern regions. In our analysis Austria, Switzerland, Bavaria, and Baden-Württemberg comprised the southern region, and all other states of Germany were defined as the northern part. We also hypothesised that different health care systems and reimbursement procedures might lead to different patterns of recommendations between countries as well as the type of hospital. To explore differences in preventive treatments recommended between northern and southern regions, countries, and type of hospital, we a priori defined these subgroups. We tested for differences between these subgroups by using Fisher's Exact Test, with a level of significance of $p \leq 0.05$ for all tests, without correction for multiple-comparisons. All calculations were completed in IBM SPSS Statistics Version 24, Armonk, NY [35].

\section{Results}

\section{Respondents}

In total, 100 hospitals participated in the survey. Of these, 18 were from Austria, 71 from Germany, and 11 from Switzerland. This is reflective of a 19\% (100/533) response-rate. These questionnaires summed up experience in 3.119 SAD patients over a two-year period $(2014 / 2015)$. For further details on participating hospitals see Table 1.

\section{Proportion of hospitals recommending preventive treatment and timing}

The majority (84\%) of the 96 psychiatric hospitals and departments that answered this question recommend the use of preventive interventions in order to reduce the risk of the onset of a new depressive episode in the upcoming fall/winter season in patients with a history of SAD. There is no consensus, however, on the optimal timing for preventive treatment in general: $38 \%(n=81)$ recommend continuing acute treatment of SAD throughout the summer, 31\% $(n=81)$ recommend to their patients to start with the preventive intervention as long as they are in remission and before depressive symptoms start (i.e. at end of summer), and $14 \%(n=81)$ tell their patients to start with preventive treatment as soon as they feel mild depressive symptoms. The remaining institutions (17\%,
Table 1 Characteristics of participating hospitals

\begin{tabular}{ll}
\hline Characteristics & $\begin{array}{l}\text { Number of hospitals } \\
\text { (response in \%) }\end{array}$ \\
\hline Country $(n=100)$ & $18(18 \%)$ \\
Austria & $71(71 \%)$ \\
Germany & $11(11 \%)$ \\
Switzerland & \\
Type of hospital ( $n=99)$ & $21(21 \%)$ \\
University hospital & $23(23 \%)$ \\
Teaching hospital & $33(33 \%)$ \\
Specialized psychiatric hospital & $22(22 \%)$ \\
Psychiatric department in general hospital & \\
Patients treated because of acute SAD in & \\
2014/2015 ( $n=92)$ & $14(15 \%)$ \\
0\% SAD patients treated 2014/2015 & $58(63 \%)$ \\
$\leq 5 \%$ of patients treated because of SAD & $13(14 \%)$ \\
$5,1 \%-10 \%$ of patients treated because of SAD & $5(5 \%)$ \\
$\geq 10 \%$ of patients treated because of SAD & \\
Interventions used to treat acute SAD ( $n=86)$ & $85(99 \%)$ \\
Antidepressants & $78(91 \%)$ \\
Lifestyle changes & $75(87 \%)$ \\
Light therapy & $73(85 \%)$ \\
Psychotherapy & $61(71 \%)$ \\
Agomelatine & $47(56 \%)$ \\
Dietary changes & \\
Mlternative methods (e.g. meditation) & \\
Methylphenidate & $(20 \%)$ \\
\hline
\end{tabular}

$\mathrm{n}$, total number of participating hospitals that answered this question; $S A D$, seasonal affective disorder

$n=81)$ use all three approaches, depending on the type of preventive treatment.

\section{Types of interventions recommended for preventive treatment}

The most common types of recommended preventive interventions are lifestyle changes and antidepressants (Fig. 1).

Eighty-five percent of hospitals and departments (69/81) consider lifestyle changes a viable preventive treatment option. Those who recommend lifestyle adjustment, suggest it on average to $83 \%$ of their patients with a history of SAD. More than half of institutions recommend a permanent lifestyle change. Suggested lifestyle changes comprise exercise on a regular basis, exercise outdoors, spending time outdoors in the sunlight, striving towards a regular sleep-wake cycle, partaking in enjoyable activities (e.g. hobbies, meeting friends), spending their winter vacations in sunny regions, and trying to redecorate the home to make it brighter (Table 2). 


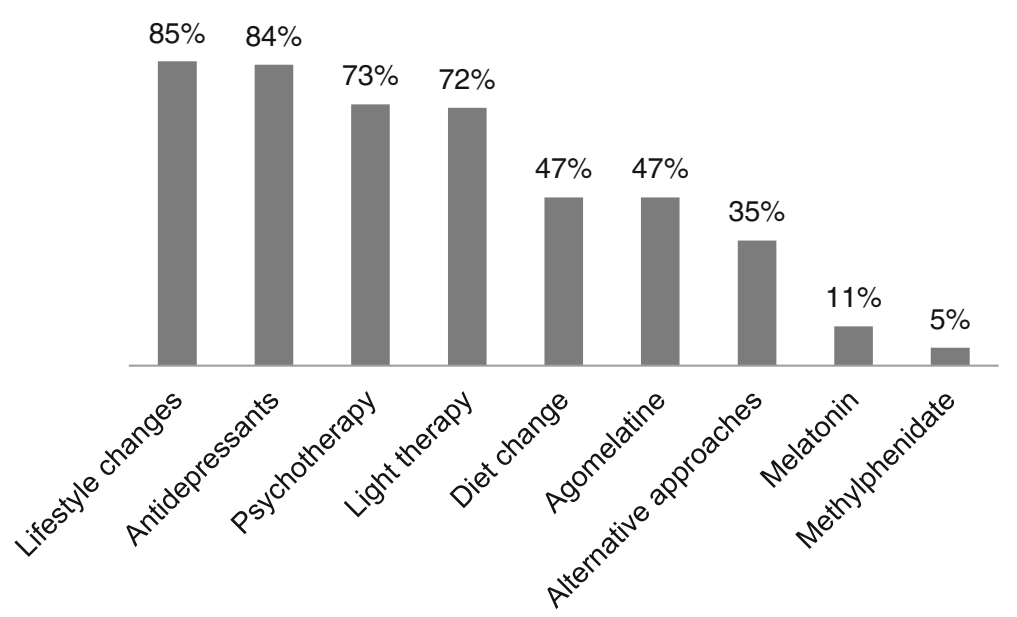

Fig. 1 Percentage of hospitals recommending types of SAD prevention $(n=81)$

Most departments and hospitals also consider antidepressants an acceptable preventive treatment (68/81). On average they recommend antidepressants to $70 \%$ of their SAD patients. Institutions named a variety of antidepressants that they prescribe as preventive treatment (Table 2). Bupropion XL, the only medication licensed for prevention in SAD patients, is mentioned by $7 \%$ of the 68 institutions recommending antidepressants for prevention.

Three quarter of hospitals (59/81) recommend psychotherapy as a preventive treatment. On average they suggest it to $62 \%$ of their SAD patients. Two fifths recommend continuous psychotherapy, one fifth suggests psychotherapy that lasts up to 30 weeks. Most frequently, behavioural therapy is recommended (see Table 2).

Three quarters (58/81) consider light therapy a viable option for prevention. They recommend it on average to $64 \%$ of their SAD patients. One third recommend continuation of light therapy throughout summer to their patients, while nearly half of the departments and hospitals recommend stopping during summer and starting by the end of summer before depressive symptoms occur. Most of the departments and hospitals recommend a light therapy device with 10,000 lux (Table 2).

Nearly half of the participating departments and hospitals (38/81) recommend diet changes. On average they suggest this to $71 \%$ of their SAD patients. Most advise a permanent change and advise cutting out caffeine, nicotine, and alcohol consumption, maintaining a balanced diet (e.g. Mediterranean diet), drinking enough fluids, adding vitamin $\mathrm{D}$ to their diet and trying to avoid heavy meals in the evening (Table 2).

Half of the hospitals recommend alternative approaches such as yoga, acupuncture, meditation or other relaxation techniques as preventive treatments to half of their SAD patients. Nearly half of the hospitals recommend agomelatine, and only a few hospitals melatonin (9/81), or methylphenidate (4/81, further details Table 2 ).

We found no differences in recommendations of preventive interventions between countries, regions and type of hospital (Table 3).

Comparing different types of preventive treatments between northern and southern regions, showed no statistically significant differences, except for one: $61 \%$ of hospitals and departments in northern regions recommend agomelatine, compared to $37 \%$ in southern regions (Table 4 ).

\section{Discussion}

SAD causes a great burden of disease. However, with the exception of our study, no data exists to date in regards to what measures psychiatric hospitals and departments recommend to their patients in order to prevent the onset of new depressive episodes. In the present study, we observed for the first time that most hospitals prefer to suggest preventive measures before the actual onset of SAD, during the months preceding fall/winter. Most hospitals used different types of preventive treatments, indicating that prevention strategies comprise a mix of interventions and not solely one specific treatment option. In addition, a novel observation was made whereby the changes in life style and the use of antidepressants were the most prevalent forms of preventive treatment recommended by hospitals.

The use of preventive treatment is high with $84 \%$ of psychiatric hospitals and departments recommending it to patients with a history of SAD, even though clinical practice guidelines do not recommend preventive treatment for SAD [28] and hardly any evidence on efficacy and safety of preventive treatments in SAD patients exist 
Table 2 Details on type, frequency, and timing of preventive interventions recommended in clinical practice

\begin{tabular}{|c|c|c|c|c|}
\hline Preventive intervention & $\begin{array}{l}\text { Hospitals recommending } \\
\text { intervention }\end{array}$ & $\begin{array}{l}\text { Average percentage of SAD } \\
\text { patients being given this } \\
\text { recommendation (min-max) }\end{array}$ & $\begin{array}{l}\text { Timing of preventive } \\
\text { intervention }\end{array}$ & $\begin{array}{l}\text { Type of preventive } \\
\text { intervention recommended } \\
\text { (multiple mentions possible) }\end{array}$ \\
\hline Lifestyle changes & $85 \%(69 / 81)$ & $83 \%(10 \%-100 \%)$ & $\begin{array}{l}\text { - } 12 \%(8 / 69) \text { recommend starting } \\
\text { with lifestyle changes by the } \\
\text { end of summer for } 4-32 \text { weeks } \\
\text { - } 64 \% \text { (44/69) recommend } \\
\text { continuous lifestyle changes } \\
\text { throughout the whole year } \\
\cdot 24 \%(17 / 69) \text { no response }\end{array}$ & $\begin{array}{l}\text { Based on } 69 \text { hospitals } \\
\text { recommending lifestyle changes: } \\
\text { - Regular exercise (41\%) } \\
\text { - Regular exercise outdoor (14\%) } \\
\text { - Do things you like (hobbies, } \\
\text { meeting friends) }(13 \%) \\
\text { - Find ways to relax (14\%) } \\
\text { - Sleep hygiene (13\%) } \\
\text { - Ensure stable day/night } \\
\text { rhythm (13\%) } \\
\text { - Spending time outdoor (9\%) } \\
\text { - Structured lifestyle (7\%) } \\
\text { - Redecorate rooms to make } \\
\text { them brighter (4\%) } \\
\text { - Winter vacation in a sunny } \\
\text { region (3\%) }\end{array}$ \\
\hline Antidepressants & $84 \%(68 / 81)$ & $70 \%(10 \%-100 \%)$ & $\begin{array}{l}\cdot 21 \%(14 / 68) \text { recommend } \\
\text { starting preventive treatment } \\
\text { by the end of summer for } \\
4-28 \text { weeks } \\
\cdot 62 \%(42 / 68) \text { recommend } \\
\text { continuous intake of } \\
\text { antidepressants throughout } \\
\text { the whole year } \\
\cdot 17 \%(12 / 68) \text { no response }\end{array}$ & $\begin{array}{l}\text { Based on } 68 \text { hospitals } \\
\text { recommending antidepressants: } \\
\text { Selective serotonin reuptake } \\
\text { inhibitors (SSRI) } \\
\text { - Citalopram (10\%), Escitalopram } \\
\text { (12\%), Sertraline (10\%) } \\
\text { - Not further specified (40\%) } \\
\text { Selective serotonin and } \\
\text { norepinephrine reuptake inhibitors } \\
\text { (SSNRI) } \\
\text { - Venlafaxine (22\%), Duloxetine } \\
\text { (4\%), Milnacipran (1\%) } \\
\text { - Not further specified (19\%) } \\
\text { Monoamine oxidase inhibitors } \\
\text { (MAO-H) } \\
\text { - Moclobemide (1\%), Not further } \\
\text { specified (6\%) } \\
\text { Noradrenergic and specific } \\
\text { serotonergic antidepressant } \\
\text { (NaSSA) } \\
\text { - Mirtazapine (19\%), Not further } \\
\text { specified (6\%) } \\
\text { Serotonin antagonist and } \\
\text { reuptake inhibitor (SARI) } \\
\text { - Trazodone (3\%) } \\
\text { Norepinephrine and dopamine } \\
\text { reuptake inhibitor (NDRI) } \\
\text { - Bupropion (7\%) } \\
\text { Tryclic antidepressant (TZA) } \\
\text { - Amitriptyline (3\%) } \\
\text { Serotonin modulators and } \\
\text { stimulators: } \\
\text { - Vortioxetine (3\%) }\end{array}$ \\
\hline Psychotherapy & $73 \%(59 / 81)$ & $62 \%(10 \%-100 \%)$ & $\begin{array}{l}\cdot 22 \%(13 / 59) \text { recommend } \\
\text { starting preventive } \\
\text { psychotherapy by the end of } \\
\text { summer for } 1-30 \text { weeks } \\
\text { - } 41 \%(30 / 59) \text { recommend } \\
\text { continuous psychotherapy } \\
\text { throughout the whole year } \\
\cdot 27 \%(16 / 59) \text { no response }\end{array}$ & $\begin{array}{l}\text { Based on } 59 \text { hospitals } \\
\text { recommending psychotherapy: } \\
\text { - Behavioural therapy }(32 \%) \\
\text { - Analytic psychotherapy }(10 \%) \\
\text { - Psychotherapy not otherwise } \\
\text { specified (7\%) } \\
\text { - Talking therapy (3\%) } \\
\text { - Psychoeducation ( } 2 \%) \\
\text { - Family therapy (2\%) } \\
\text { - Hypnotherapy ( } 2 \%) \\
\text { - Systemic therapy (2\%) }\end{array}$ \\
\hline
\end{tabular}


Table 2 Details on type, frequency, and timing of preventive interventions recommended in clinical practice (Continued)

\begin{tabular}{|c|c|c|c|c|}
\hline Light therapy & $72 \%(58 / 81)$ & $64 \%(10 \%-100 \%)$ & $\begin{array}{l}\text { - } 47 \%(27 / 58) \text { recommend to } \\
\text { start preventive light therapy } \\
\text { by the end of summer for } \\
3-16 \text { weeks } \\
\text { - } 31 \%(18 / 58) \text { recommend } \\
\text { continuous use of light therapy } \\
\text { throughout the whole year } \\
\text { - } 22 \%(13 / 58) \text { no response }\end{array}$ & $\begin{array}{l}\text { Based on } 58 \text { hospitals } \\
\text { recommending light therapy: } \\
\text { - Light therapy device with } \\
10,000 \text { Ix (40\%) } \\
\text { - Spending time in natural } \\
\text { sunlight (12\%) } \\
\text { - Light therapy device with } \\
6000 \text { Ix (3\%) } \\
\text { - Light therapy device with } \\
2000 \text { Ix (2\%) } \\
\text { - Light therapy device with } \\
200 \text { Ix (2\%) } \\
\text { - Infrared light (2\%) } \\
\text { - Light visor (2\%) } \\
\text { - "Light shower" (2\%) }\end{array}$ \\
\hline Diet change & $47 \%(38 / 81)$ & $71 \%(10 \%-100 \%)$ & $\begin{array}{l}\text { - } 11 \%(4 / 38) \text { recommend to } \\
\text { start diet changes by the end } \\
\text { of summer for } 8-26 \text { weeks } \\
\text { - } 61 \%(23 / 38) \text { recommend } \\
\text { continuous diet change } \\
\text { throughout the whole year } \\
\text { - } 29 \%(11 / 38) \text { no response }\end{array}$ & $\begin{array}{l}\text { Based on } 38 \text { hospitals } \\
\text { recommending diet changes: } \\
\text { - Balanced diet, e.g. } \\
\text { Mediterranean diet, less } \\
\text { carbohydrates, more fibres, less } \\
\text { meat }(47 \%) \\
\text { - Less coffee }(24 \%) \\
\text { - Less nicotine }(11 \%) \\
\text { - Less alcohol (11\%) } \\
\text { - Vitamin D (8\%) } \\
\text { - No heavy meals in the } \\
\text { evenings (8\%) } \\
\text { - Nutritional Supplements, e.g. } \\
\text { Vitamin B12, iron (5\%) } \\
\text { - Increased fluid intake (3\%) }\end{array}$ \\
\hline Agomelatine & $47 \%(38 / 81)$ & $24 \%(10 \%-70 \%)$ & $\begin{array}{l}\cdot 21 \%(8 / 38) \text { recommend to start } \\
\text { by the end of summer for } \\
4-36 \text { weeks } \\
\cdot 58 \%(22 / 38) \text { recommend } \\
\text { continuous intake } \\
\cdot 21 \%(8 / 38) \text { no response }\end{array}$ & $\begin{array}{l}\text { Based on } 38 \text { hospitals } \\
\text { recommending agomelatine: } \\
\text { - Agomelatine }(66 \%)\end{array}$ \\
\hline Alternative approaches & $35 \%(28 / 81)$ & $57 \%(10 \%-100 \%)$ & $\begin{array}{l}\text { - } 18 \%(5 / 28) \text { recommend to start } \\
\text { preventive alternative } \\
\text { treatments by the end of } \\
\text { summer for } 4-32 \text { weeks } \\
\text { - } 68 \%(19 / 28) \text { recommend } \\
\text { continuous treatment } \\
\text { throughout the whole year } \\
\text { - } 14 \%(4 / 28) \text { no response }\end{array}$ & $\begin{array}{l}\text { Based on } 28 \text { hospitals } \\
\text { recommending alternative } \\
\text { treatments: } \\
\text { - Yoga (29\%) } \\
\text { - Relaxation techniques (29\%) } \\
\text { - Acupuncture (21\%) } \\
\text { - Meditation (14\%) } \\
\text { - Progressive muscle } \\
\text { relaxation (14\%) } \\
\text { - Homeopathy (4\%) } \\
\text { - Aroma therapy (4\%) } \\
\text { - Sleep deprivation (4\%) } \\
\text { - Kinesiology (4\%) } \\
\text { - Tai Chi (4\%) } \\
\text { - Chi Gong (4\%) } \\
\text { - Shiatsu (4\%) } \\
\text { - Reiki (4\%) }\end{array}$ \\
\hline Melatonin & $11 \%(9 / 81)$ & $23 \%(10 \%-70 \%)$ & $\begin{array}{l}\cdot 78 \%(7 / 9) \text { recommend to start } \\
\text { by the end of summer for } \\
3-30 \text { weeks } \\
\cdot 11 \%(1 / 9) \text { recommend } \\
\text { continuous treatment } \\
\cdot 11 \%(1 / 9) \text { no response }\end{array}$ & $\begin{array}{l}\text { Based on } 9 \text { hospitals } \\
\text { recommending melatonin: } \\
\text { - Melatonin (33\%) }\end{array}$ \\
\hline Methylphenidate & $5 \%(4 / 81)$ & $10 \%(10 \%-10 \%)$ & $\begin{array}{l}\cdot 1 \text { institution recommends } \\
\text { preventive treatment for } \\
12 \text { weeks } \\
\cdot 2 \text { institutions recommend } \\
\text { continuous treatment } \\
\cdot 1 \text { institution did not respond }\end{array}$ & $\begin{array}{l}\text { Based on } 4 \text { hospitals } \\
\text { recommending methylphenidate } \\
\text { - Methylphenidate (50\%) }\end{array}$ \\
\hline
\end{tabular}


Table 3 Differences in use of preventive treatment between countries, type of hospital, and region

\begin{tabular}{llc}
\hline Subgroups & $\begin{array}{l}\text { Use of preventive } \\
\text { treatment }\end{array}$ & $\begin{array}{c}\text { Fisher's } \\
p \text {-value }\end{array}$ \\
\hline Country $(n=96)$ & & 0.134 \\
$\quad$ Austria $(n=18)$ & $94 \%$ & \\
$\quad$ Germany $(n=67)$ & $79 \%$ & \\
$\quad$ Switzerland $(n=11)$ & $100 \%$ & 0.923 \\
Type of hospital $(n=95)$ & & \\
$\quad$ University hospital $(n=20)$ & $85 \%$ & \\
$\quad$ Teaching hospital $(n=22)$ & $82 \%$ & \\
$\quad$ Specialized psychiatric hospital $(n=32)$ & $90 \%$ & 0.261 \\
$\quad$ Psychiatric department in general & $81 \%$ & \\
$\quad$ hospital $(n=21)$ & & \\
Northern vs. southern regions $(n=95)$ & & \\
$\quad$ South $(n=47)$ & $89 \%$ & \\
$\quad$ North $(n=48)$ & $79 \%$ &
\end{tabular}

$\mathrm{n}$, total number of participating hospitals that answered this question $S A D$ seasonal affective disorder

[24-26, 36]. In order to provide psychiatrists with guidance on preventive treatment, controlled studies investigating the efficacy and harm of different preventive interventions and comparing them with each other are needed.

Interventions recommended most frequently for prevention are lifestyle changes, antidepressants, light therapy, and psychotherapy. Respondents reported prescribing a wide variety of antidepressants, although only one (Bupropion XL) is licenced for this indication. One explanation could be that psychiatrists often define it as preventive use to continue acute treatment with antidepressant throughout the summer. In this case they seem to select from all types of antidepressants, probably considering effectiveness and side effects of antidepressants in prior acute treatment periods.

This is in line with another interesting finding, in that the use of acute treatment options for acute SAD is very similar to the use of these interventions as preventive treatment. This could be because psychiatrists and patients are more willing to use an intervention in a symptom-free time as prevention, when this intervention has already proven effective in the acute, depressive phase.

About three quarters used light therapy for acute and preventive treatment of SAD. This agrees with another study that showed that $79 \%$ of institutions considered light therapy useful in acute SAD treatment [31].

Comparisons between northern and southern regions revealed no differences in the use of preventive treatments and type of preventive interventions recommended, although higher prevalence of SAD in northern latitude [3-7, 37] would suggest higher demand for preventive treatment. The only difference identified was that agomelatine is prescribed more often in northern regions. This might be because this medication gets reimbursed only in Germany.

There are some limitations to this study: First, not all addressed institutions participated in our survey. The response rate $(19 \%)$ was moderate. However, response rates around $20 \%$ are common in postal and web-based surveys [30]. It is possible that especially institutions that do not treat patients for SAD refrained from participating in our survey, which may have introduced a selection bias. However, we assume that only institutions that treat SAD patients can recommend preventive treatment to them. Therefore, the selection bias likely did not substantially influence our results.

A further shortcoming of this study is that the numbers reported from all respondents are their best estimates and are not based on actual documentation. This trade-off was necessary to make completing the survey feasible within a decent time frame. However, this may have introduced bias, such as heads of departments remembering some types of preventive treatments better than others.

Third, we focused on psychiatric hospitals and departments, not on office-based general practitioners and

Table 4 Differences between type of preventive treatment between northern and southern regions

\begin{tabular}{llll}
\hline Type of preventive treatment & North & South & Fisher's $p$-value \\
\hline Antidepressants & $90 \%(n=38)$ & $83 \%(n=40)$ & 0.519 \\
Lifestyle changes & $87 \%(n=37)$ & $88 \%(n=41)$ & 1.000 \\
Psychotherapy & $73 \%(n=37)$ & $76 \%(n=41)$ & 0.802 \\
Light Therapy & $72 \%(n=39)$ & $73 \%(n=40)$ & 1.000 \\
Agomelatine & $61 \%(n=38)$ & $37 \%(n=41)$ & $0.044^{\mathrm{a}}$ \\
Dietary suggestions & $49 \%(n=37)$ & $50 \%(n=40)$ & 1.000 \\
Alternative approaches & $38 \%(n=37)$ & $34 \%(n=41)$ & 0.815 \\
Melatonin & $5 \%(n=37)$ & $17 \%(n=41)$ & 0.159 \\
Methylphenidate & $0 \%(n=37)$ & $10 \%(n=41)$ & 0.117 \\
\hline
\end{tabular}

${ }^{\text {a }}$ Statistically significant

$\mathrm{n}$, total number of participating hospitals that answered this question 
psychiatrists who might be the first point of contact for many SAD patients. We did not survey general practitioners because studies have shown that SAD is often under- or misdiagnosed in this setting [5]. Goldberg and Bridges [38] assume that this is because it may be difficult for general practitioners to recognize forms of depression that are characterized by atypical symptoms such as weight gain, fatigue and hypersomnia, all of which commonly occur in SAD. However, for future studies it may be interesting to investigate recommendation of preventive strategies by office-based general practitioners and psychiatrists in SAD patients, especially in light of new findings indicating that $60 \%$ of depression-related treatment in Germany is provided by general practitioners [39].

\section{Conclusions}

Preventive treatment in patients with a history of SAD is very common in clinical practice in German-speaking countries and a wide variety of treatment options is used. However, the evidence on efficacy and harms of preventive treatment in SAD patients is limited. At the moment, psychiatrists seem to draw conclusions from efficacy of acute treatment of SAD to efficacy of preventive treatment. To assist psychiatrists and patients in decision making and provide guidance, controlled comparative effectiveness studies on preventive treatment are needed. Considering the current lack of evidence, the selection of treatment for preventing winter depression should be strongly based on patient preferences. Therefore studies on patients' satisfaction and perceived benefit to those interventions are needed.

\section{Abbreviations}

Max: Highest percentage named; Min: Lowest percentage named; n: Total number of hospitals answering this question; SAD: Seasonal affective disorder; $\mathrm{XL}$ : Extended release

\section{Acknowledgements}

We wish to thank all respondents for their participation in the survey and Prof. Gerald Gartlehner for his valuable feedback on the manuscript.

\section{Funding}

This research did not receive any specific grant from funding agencies in the public, commercial, or not-for-profit sectors.

\section{Availability of data and materials}

The dataset generated and analysed during the current study is not publicly available due to privacy reasons of participants but is available from the corresponding author on reasonable request.

\section{Authors' contributions}

DW and BNS designed the study and wrote the study protocol. EP, SK, and MS critically revised the protocol. DW and BNS registered the protocol with the ethical review board of the Medical University of Vienna. BNS developed the questionnaire, conducted the survey, and undertook the statistical analysis. DW, EP, MS, and SK gave feedback to the questionnaire and input for the analysis. BNS wrote the first draft of the manuscript. DW, EP, SK, MS revised the manuscript. All authors read and approved the final manuscript.

\section{Ethics approval and consent to participate}

The study was approved by and registered with the ethical review board of the Medical University of Vienna (EC No 1586/2015). On the cover-page of the questionnaire participants were informed about the aim of the study and were guaranteed that all given information will be presented in an anonymized way. Participation was voluntary and by starting the survey they consented to participate.

\section{Consent for publication}

Not applicable.

\section{Competing interests}

Without any relevance to this work, SK received grants/research support, consulting fees and/or honoraria within the last 3 years from Angelini, AOP Orphan Pharmaceuticals AG, AstraZeneca, Eli Lilly, Janssen, KRKA-Pharma, Lundbeck, Neuraxpharm, Pfizer, Pierre Fabre, Schwabe and Servier. MS has received travel grants from Janssen, Eli Lilly, and AOP Orphan Pharmaceuticals, speaker honoraria from Janssen, workshop participation from Eli Lilly, and is recipient of a NARSAD young investigator grant. DW has received lecture fees from Angelini, Lundbeck, and Pfizer.

BNS and EP declare that they have no competing interests.

\section{Publisher's Note}

Springer Nature remains neutral with regard to jurisdictional claims in published maps and institutional affiliations.

\section{Author details}

${ }^{1}$ Department of Psychiatry and Psychotherapy, Medical University of Vienna, Währinger Gürtel 18-20, 1090 Vienna, Austria. ${ }^{2}$ Department for

Evidence-based Medicine and Clinical Epidemiology, Danube-University Krems, Dr.-Karl-Dorrek Strasse 30, 3500, Krems a.d. Donau, Austria.

Received: 2 March 2017 Accepted: 27 June 2017

Published online: 11 July 2017

\section{References}

1. American Psychiatric Association. Diagnostic and statistical manual of mental disorders (5th edition). Washington, DC: American Psychiatric Association; 2013.

2. Rosenthal NE, Sack DA, Gillin JC, Lewy AJ, Goodwin FK, Davenport Y, et al. Seasonal affective disorder. A description of the syndrome and preliminary findings with light therapy. Arch Gen Psychiatry. 1984;41(1):72-80.

3. Magnusson A, Stefansson JG. Prevalence of seasonal affective disorder in Iceland. Arch Gen Psychiatry. 1993:50:941-6.

4. Mersch PP, Middendorp HM, Bouhuys AL, Beersma DG, van den Hoofdakker $\mathrm{RH}$. The prevalence of seasonal affective disorder in The Netherlands: a prospective and retrospective study of seasonal mood variation in the general population. Biol Psychiatry. 1999:45:1013-22.

5. Michalak EE, Wilkinson C, Dowrick C, Wilkinson G. Seasonal affective disorder: prevalence, detection and current treatment in North Wales. Br J Psychiatry. 2001;179:31-4.

6. Muscettola G, Barbato G, Ficca G, Beatrice M, Puca M, Aguglia E, et al. Seasonality of mood in Italy: role of latitude and sociocultural factors. J Affect Disord. 1995;33:135-9.

7. Rastad C, Sjoden PO, Ulfberg J. High prevalence of self-reported winter depression in a Swedish county. Psychiatry Clin Neurosci. 2005;59:666-75.

8. Pjrek E, Baldinger-Melich P, Spies M, Papageorgiou K, Kasper S, Winkler D. Epidemiology and socioeconomic impact of seasonal affective disorder in Austria epidemiology and socioeconomic impact of seasonal affective disorder in Austria. Europ Psychiatry. 2016;32:28-32.

9. Wirz-Justice A, Graw P, Krauchi K, Wacker HR. Seasonality in affective disorders in Switzerland. Acta Psychiatr Scand. 2003;Suppl 108:92-5.

10. Winkler D, Praschak-Rieder N, Willeit M, Lucht M, Hilger E, Konstantinidis A, Stastny J, Thierry N, Pjrek E, Neumeister A, Möller HJ, Kasper S. Saisonal abhängige Depression (SAD) in zwei deutschsprachigen Universitätszentren: Bonn, Wien. Nervenarzt. 2002;73:637-43.

11. Magnusson A, Partonen T. The diagnosis, symptomatology, and epidemiology of seasonal affective disorder. CNS Spectrum. 2005;10(8):625-34

12. Schwartz PJ, Brown C, Wehr TA, Rosenthal NE. Winter seasonal affective disorder: a follow-up study of the first 59 patients of the National Institute of Mental Health seasonal studies program. Am J Psychiatr. 1996;153(8):1028-36. 
13. Terman M, Terman JS. Light therapy for seasonal and nonseasonal depression: efficacy, protocol, safety, and side effects. CNS Spectrums. 2005;10:647-63.

14. Neumeister A, Konstantinidis A, Praschak-Rieder N, Willeit M, Hilger E, Stastny J, Kasper S. Monoaminergic function in the pathogenesis of seasonal affective disorder. Int J Neuropsychopharmacol. 2001;4:409-20.

15. Modell JG, Rosenthal NE, Harriett AE, Krishen A, Asgharian A, Foster VJ, et al. Seasonal affective disorder and its prevention by anticipatory treatment with bupropion XL. Biol Psychiatry. 2005;58(8):658-67.

16. Pjrek E, Winkler D, Konstantinidis A, Willeit M, Praschak-Rieder N, Kasper S. Agomelatine in the treatment of seasonal affective disorder. Psychopharmacology. 2007;190(4):575-9.

17. Lewy AJ, Emens J, Jackman A, Yuhas K. Circadian uses of melatonin in humans. Chronobiol Int. 2006;23(1-2):403-12.

18. Hodges S, Marks M. Cognitive characteristics of seasonal affective disorder: a preliminary investigation. J Affect Disord. 1998;50:59-64.

19. Levitan RD, Rector NA, Bagby M. Negative attributional style in seasonal affective disorder. Am J Psychiatr. 1998;155:428-30.

20. Rohan KJ, Evans M, Mahon JN, Sitnikov L, Ho SY, Nillni Yl, et al. Cognitivebehavioral therapy vs. light therapy for preventing winter depression recurrence: study protocol for a randomized controlled trial. Trials. 2013;14:82.

21. Rohan KJ, Sigmon ST, Dorhofer DM. Cognitive-behavioral factors in seasonal affective disorder. J Consult Clin Psychol. 2003;71:22-30.

22. Danilenko KV, Plisov IL, Hebert M, Kräuchi K, Wirz-Justice A. Influence of timed nutrient diet on depression and light sensitivity in seasonal affective disorder. Chronobiol Int. 2008:25:51-64.

23. Westrin A, Lam RW. Long-term and preventative treatment for seasonal affective disorder. CNS Drugs. 2007;21(11):901-9.

24. Gartlehner G, Nussbaumer B, Gaynes BN, et al. Second-generation antidepressants for preventing seasonal affective disorder in adults. Cochrane Database Syst Rev. 2015;(11):CD011268. doi:10.1002/14651858. CD011268.pub2

25. Nussbaumer B, Kaminski-Hartenthaler A, Forneris CA, et al. Light therapy for preventing seasonal affective disorder. Cochrane Database Syst Rev. 2015(11):CD011269. doi:10.1002/14651858.CD011269.pub2.

26. Kaminski-Hartenthaler A, Nussbaumer B, Forneris CA, Morgan LC, et al. Melatonin and agomelatine for preventing seasonal affective disorder. Cochrane Database Syst Rev. 2015;(11):CD011271. doi:10.1002/14651858. CD011271.pub2.

27. Rohan K, Meyerhoff J, Ho SY, Evans M, Postolache TT, Vacek PM. Outcomes one and two winters following cognitive-behavioral therapy or light therapy for seasonal affective disorder. Am J Psychiatry. 2016;173(3):244-51.

28. DGPPN, BÄK, KBV, AWMF, AkdÄ, BPtK, BApK, DAGSHG, DEGAM, DGPM, DGPs, DGRW (Hrsg.) für die Leitliniengruppe Unipolare Depression, S3-Leitlinie/ Nationale Versorgungs-Leitlinie Unipolare Depression - Langfassung, 2nd Edition. Version 4. 2015. www.depression.versorgungsleitlinien.de. Accessed 22 Feb 17. doi:10.6101/AZQ/000329

29. DKA (Deutsches Krankenhausadressbuch). Rombach Verlag, Freiburg, 2015.

30. Porst R. Fragebogen - ein Arbeitsbuch. Studienskripten zur Soziologie. Wiesbaden: Verlag für Sozialwissenschaften; 2013.

31. Fischer R, Kasper S, Pjrek E, Winkler D. On the application of light therapy in German-speaking countries. Eur Arch Psychiatry Clin Neurosci. 2012;262: 501-5.

32. SurveyMonkey. Software to conduct web-based surveys, 2016. https://www. surveymonkey.co.uk/. Accessed 22 Feb 2017.

33. Klimadaten von Österreich 1971-2000 - Wien-Innere-Stadt. Central Institute for Meteorology and Geodynamics. http://www.zamg.ac.at/fix/klima/oe7100/klima2000/klimadaten_oesterreich_1971_frame1.htm. Retrieved 6 May 2017.

34. Climate Observation Germany. http://www.dwd.de/DE/klimaumwelt/ klimaueberwachung/deutschland/deutschland_node.html. Retrieved 6 May 2017.

35. IBM Corp. IBM SPSS Statistics for Windows, version 24.0. Armonk: IBM Corp.; 2015

36. Forneris CA, Nussbaumer B, Kaminski-Hartenthaler A, et al. Psychological therapies for preventing seasonal affective disorder. Cochrane Database Syst Rev. 2015;(11):CD011270. doi:10.1002/14651858.CD011270.pub2.
37. Dam H, Jakobsen K, Mellerup E. Prevalence of winter depression in Denmark. Acta Psychiatr Scand. 1998:97:1-4.

38. Goldberg DP, Bridges K. Somatic presentations of psychiatric illness in primary care setting. J Psychosom Res. 1988;32:137-44.

39. Wagner CJ, Metzger FG, Sievers C, Marschall U, L'hoest H, Stollenwerk B, Stock S. Depression-related treatment and costs in Germany: do they change with comorbidity? A claims data analysis. J Affect Disord. 2016;193: 257-66.

\section{Submit your next manuscript to BioMed Central and we will help you at every step:}

- We accept pre-submission inquiries

- Our selector tool helps you to find the most relevant journal

- We provide round the clock customer support

- Convenient online submission

- Thorough peer review

- Inclusion in PubMed and all major indexing services

- Maximum visibility for your research

Submit your manuscript at www.biomedcentral.com/submit

) Biomed Central 